\title{
Gamma delta T cells are early responders to Mycobacterium avium ssp. paratuberculosis in colostrum-replete Holstein calves
}

\author{
L. A. Krueger, ${ }^{\dagger} \dagger$ D. C. Beitz, ${ }^{*}$ S. B. Humphrey, $\ddagger$ and J. R. Stabel ${ }^{*} \dagger^{1}$ \\ *Department of Animal Science, lowa State University, Ames 50011 \\ †Infectious Bacterial Diseases Research Unit, and \\ ‡Microscopy Services, National Animal Disease Center, Agricultural Research Service, USDA, Ames, IA 50010
}

\begin{abstract}
Peripheral blood mononuclear cells (PBMC) and mesenteric node lymphocytes (MNL) were obtained from 30 calves that were assigned randomly at birth to 1 of 6 treatment groups with 5 calves per treatment in a 14-d study: (1) colostrum-deprived (CD), no vitamins; (2) colostrum-replacer (CR), no vitamins; (3) $\mathrm{CR}$, vitamin $\mathrm{A}$; (4) $\mathrm{CR}$, vitamin $\mathrm{D}_{3}$; (5) $\mathrm{CR}$, vitamin $\mathrm{E}$; (6) $\mathrm{CR}$, vitamins $\mathrm{A}, \mathrm{D}_{3}$, E. Calves were injected with appropriate vitamin supplements and fed pasteurized whole milk (CD calves) or fractionated colostrum replacer (CR calves) at birth. Thereafter, all calves were fed pasteurized whole milk fortified with vitamins according to treatment group. Calves were orally inoculated with $10^{8}$ cfu of Mycobacterium avium ssp. paratuberculosis (MAP) on $\mathrm{d} 1$ and 3 . The PBMC and MNL harvested on d 13 were analyzed by flow cytometry as fresh cells, after 3-d culture with phytohemagglutinin (PHA), and after 6-d culture with a whole-cell sonicate of MAP (MPS). Peripheral $\gamma \delta$ T cells were a predominant lymphocyte subset in neonatal calves, with a decreased percentage noted in CD calves compared with CR calves. As well, CD25 expression was higher in $\gamma \delta \mathrm{T}$ cells compared with other cell subsets, regardless of treatment group. Stimulation of PBMC with PHA resulted in increased $\mathrm{CD} 4^{+}$and $\mathrm{CD} 8^{+}$subsets, whereas MNL response was dominated by expansion of B-cell subpopulations. Stimulation with PHA and MPS decreased the relative abundance of PBMC $\gamma \delta \mathrm{T}$ cells, but MNL $\gamma \delta$ T cells increased upon stimulation with MPS. These results identify $\gamma \delta \mathrm{T}$ cells as key early responders to intracellular infection in neonatal calves and suggest that colostrum may be an important mediator of this response.
\end{abstract}

Received March 7, 2016.

Accepted July 27, 2016.

${ }^{1}$ Corresponding author: judy.stabel@ars.usda.gov
Key words: dairy calf, colostrum, vitamins, cellular immunity

\section{INTRODUCTION}

At parturition, neonatal calves are susceptible to infection by Mycobacterium avium ssp. paratuberculosis (MAP), an obligate intracellular pathogen and the causative agent of Johne's disease. We know that MAP is shed in the feces of subclinically and clinically infected animals, as well as in the colostrum and milk of animals in advanced stages of Johne's disease (Streeter et al., 1995; Harris and Barletta, 2001; Stabel et al., 2014); thus, reservoirs for infection are abundant for the offspring of infected dams. As well, maternal suppression of fetal T-helper 1 (Th1) immunity during late-stage pregnancy persists into early postnatal life and could compromise neonates' ability to clear intracellular infections (Harris and Barletta, 2001; Chase et al., 2008). Mycobacterium avium ssp. paratuberculosis is known to subsequently survive phagocytosis by macrophages and replicate intracellularly during a long subclinical latency (Harris and Barletta, 2001). Little is known, however, about adaptive immune responses to this pathogen during the early neonatal period.

Neonatal calves are born immunologically naïve but may also be considered immunosuppressed because of hormonal effects from the dam (Chase et al., 2008). Bovine colostrum contains non-nutritive compounds that complement the immunosuppressed state of the neonate by neutralizing pathogens and enabling tolerant responses during immune development (Stelwagen et al., 2009). Originally attributed solely to passively transferred $\operatorname{IgG}_{1}$ (Robison et al., 1988), the immune benefits of colostrum are now also attributed to growth factors, cytokines, antimicrobial peptides, and leukocytes found in the mammary secretion (Stelwagen et al., 2009). Collectively, the non-nutritive compounds in colostrum promote T-helper 2 (Th2)-biased immune responses to early microbial encounters and prevent harmful, inappropriate inflammation in neonatal tissues (Chase et al., 2008). Postnatal nutritional influ- 
ences, such as increased dietary energy and protein or vitamin $\mathrm{A}, \mathrm{D}_{3}$, or $\mathrm{E}$ deficiencies, may cause dysregulation of immune signaling and decreased integrity of immune responses, thus compromising neonatal health (Nonnecke et al., 2010; Sacco et al., 2012; Krueger et al., 2014).

The present study was conducted to determine whether neonatal bovine leukocyte subsets recognize and respond to MAP antigens within the first $14 \mathrm{~d}$ of age, when passive immune protections wane but calf immunity is still partially naïve. We have shown that feeding colostrum replacer resulted in early acquisition of haptoglobin, a key mediator of inflammation with roles in host immunity (Krueger et al., 2016). As well, supplementation with vitamins D and E reduced the incidence of scours, suggesting that nutritional supplementation is critical for neonatal calves with undeveloped immune systems (Krueger et al., 2016). The present study was designed to test the hypothesis that colostrum, vitamin supplementation, or both would alter mononuclear cell proliferative capabilities and subsequent responses to MAP antigens.

\section{MATERIALS AND METHODS}

\section{Animals and Treatments}

Thirty Holstein bull calves were obtained at birth from 2 dairy farms in central Iowa and treated as previously described (Krueger et al., 2016). Both farms had previously participated in Johne's disease monitoring activities and had previously been used as sources of Johne's-free neonatal calves for experimental research at the National Animal Disease Center (Ames). Calves in the present study were colostrum-deprived (CD) or fed colostrum replacer at birth (CR; Milk Products, Chilton, WI). The CD group was included as a negative control for the effects of feeding colostrum and was used to compare the benefits of colostral components other than vitamins. The colostrum replacer was specially manufactured to be void of fat-soluble vitamins, so that we could use further experimental CR groups to evaluate only the effect of the supplemental vitamin(s). All calves received a first feeding within $4 \mathrm{~h}$ of birth. The CD calves were fed 1.9 L of pasteurized whole milk $\left(40^{\circ} \mathrm{C}\right.$; Iowa State University Dairy Farm, Ames, IA) as a control; calves in the remaining 5 treatment groups received $375 \mathrm{~g}$ of fractionated colostrum replacer (Milk Products, Chilton, WI) reconstituted in $1.9 \mathrm{~L}$ of water at approximately $40^{\circ} \mathrm{C}$. The colostrum replacer contained $150 \mathrm{~g}$ of bovine globulin protein concentrated from colostral whey and was considered devoid of fatsoluble vitamins $\mathrm{A}, \mathrm{D}_{3}$, and $\mathrm{E}$. Calves in the $\mathrm{CR}$ groups also received vitamin treatments at the time of first feeding and throughout the study: no supplementation (CR) or supplementation with vitamin A (CR-A), vitamin $\mathrm{D}_{3}$ (CR-D), vitamin $\mathrm{E}$ ( CR-E), or all 3 (CRADE). Calves in the vitamin treatment groups were given 3-mL s.c. injections at birth to deliver 150,000 IU of retinyl palmitate (CR-A), 150,000 IU of cholecalciferol (CR-D), or 1,500 IU of D- $\alpha$-tocopherol (CR-E). Thereafter (d 1 to 14 of study), calves assigned to the vitamin treatment groups were administered 25,000 IU of retinyl palmitate, 5,000 IU of cholecalciferol, $500 \mathrm{IU}$ of D- $\alpha$-tocopherol, respectively, orally each day in their dietary milk. Calves in the CR-ADE group received an injection or oral solution containing vitamins $\mathrm{A}, \mathrm{D}_{3}$, and $\mathrm{E}$ in the concentrations described above. Calves in the $\mathrm{CD}$ and $\mathrm{CR}$ control groups were injected with $3 \mathrm{~mL}$ of placebo carrier solution at birth (proprietary formulation; Stuart Products Inc., Bedford, TX). Thereafter, calves were fed $2.7 \mathrm{~L}$ of pasteurized whole milk, obtained from the Iowa State University Dairy Farm (Ames) as described below.

Housing and Feeding. All calves were transported within $12 \mathrm{~h}$ of birth to the National Animal Disease Center (Ames, IA) and assigned upon receipt one at a time across treatment groups, precluding any bias from location. Calves were housed indoors in individual pens elevated from a concrete floor. Ambient temperature was held at approximately $20^{\circ} \mathrm{C}$. Upon arrival, calves were placed on a twice-daily feeding schedule of 12 -h intervals, with approximate feeding times at 0600 and $1800 \mathrm{~h}$. At each feeding, calves were fed $2.7 \mathrm{~L}$ of pasteurized whole milk transported daily from the Iowa State University Dairy Farm (Ames). All calves were offered milk via bottle and nipple, but refusals of greater than $0.1 \mathrm{~L}$ were administered via esophageal tube. Calves received $1 \mathrm{~mL}$ of oral vitamin solution via dietary milk at each evening feeding, according to treatment group. The first morning feeding in the study location marked d 1 of the study.

MAP Infection. All calves were inoculated twice via ingestion of dietary milk containing $10^{8} \mathrm{cfu}$ of MAP, strain 167 (clinical isolate), during the morning feedings of d 1 and 3. After a 12-h fast, calves were killed by barbiturate injection on d $14 \pm 1$ for collection of intestinal tissues, including the ileocecal valve, ileum, jejunum, duodenum, cecum, colon, and associated lymph nodes, as described by Krueger et al. (2016). A mesenteric lymph node associated with the mid-jejunum was located by tracing the small intestine approximately $1.5 \mathrm{~m}$ from the ileum toward the duodenum until the mesenteric lymph node chain was observed. All animal procedures were approved by the Animal Care and Use Committee of the National Animal Disease Center. 


\section{Isolation and Culture of Peripheral Blood Mononuclear Cells and Mesenteric Node Lymphocytes}

On $\mathrm{d} 13 \pm 1$, before the morning feeding, $20 \mathrm{~mL}$ of blood was collected via jugular venipuncture into a syringe containing $2 \times$ acid-citrate-dextrose to isolate peripheral blood mononuclear cells (PBMC). These cells were resuspended to $2 \times 10^{6} / \mathrm{mL}$ in complete medium consisting of RPMI-1640 with $2 \mathrm{mM}$ L-glutamine and $25 \mathrm{~m} M$ HEPES (Gibco, Grand Island, NY) and supplemented with $10 \%$ fetal calf serum (Gibco), 100 $\mu \mathrm{g} / \mathrm{mL}$ streptomycin sulfate (Gibco), and $0.25 \mu \mathrm{g} / \mathrm{mL}$ amphotericin B (Gibco).

The mesenteric lymph node, obtained at d 14 necropsy, was rinsed with $0.15 M$ PBS, followed by homogenization in RPMI-1640 using a gentle-MACS Octo Dissociator with $\mathrm{C}$ tubes to disrupt the tissue (Miltenyl Biotech, San Diego, CA). Cells were resuspended to 2.0 $\times 10^{6}$ cells $/ \mathrm{mL}$ with complete RPMI-1640 medium.

The PBMC and mesenteric node lymphocytes (MNL) were cultured in replicate 48-well flat-bottomed plates (Nunc Technologies, Rochester, NY) at $39^{\circ} \mathrm{C}$ in $5 \% \mathrm{CO}_{2}$ in a humidified atmosphere. For each mononuclear cell sample, 1 plate was cultured for $24 \mathrm{~h}$, 1 plate was cultured for $3 \mathrm{~d}$, and 1 plate was cultured for $6 \mathrm{~d}$. Duplicate wells were set up for each animal for each of the following in vitro treatments: medium alone [nonstimulated (NS)], concanavalin A (10 $\mu \mathrm{g} /$ mL; Sigma, St. Louis, MO), pokeweed mitogen (10 $\mu \mathrm{g} /$ $\mathrm{mL}$; Sigma), and phytohemagglutinin (PHA; $10 \mu \mathrm{g} /$ $\mathrm{mL}$; Sigma), or a whole-cell sonicate preparation of MAP (MPS; $10 \mu \mathrm{g} / \mathrm{mL}$; Stabel et al., 2011). After 24 h, 1 set of plates was removed and centrifuged at 400 $\times g$ for $5 \mathrm{~min}$. Supernatants were removed without disturbing the cells in culture and stored at $-20^{\circ} \mathrm{C}$ before cytokine measurement. Flow cytometric analyses were also performed on cells harvested from plates containing NS and PHA treatments after incubation for $3 \mathrm{~d}$, as well as from plates containing NS and MPS after incubation for $6 \mathrm{~d}$.

\section{Flow Cytometry}

We analyzed PBMC and MNL by flow cytometry as freshly isolated cells or after 3 or $6 \mathrm{~d}$ in culture as described above. Cells were stained with primary monoclonal antibodies and secondary isotype-specific fluorochromes, or with directly conjugated monoclonal antibody-fluorochrome complexes, using 3 panels as described in Table 1. All primary antibodies were obtained from Washington State University (Pullman, WA), and all secondary fluorochromes were obtained from Southern Biotech (Birmingham, AL), except for both Alexa350 isotypes, which were purchased from Invitrogen (Grand Island, NY). Monoclonal antibodies DEC205 and BAQ29 were conjugated in-house to Oregon Green and Pacific Orange, respectively, using commercial kits (Oregon Green 488 Protein Labeling Kit and Pacific Orange Antibody Labeling Kit, Life Technologies, Carlsbad, CA). Other monoclonal antibody-fluorochrome complexes were purchased from commercial sources, including BAQ29A-PE (Becton Dickinson, Franklin Lakes, NJ) CD14-Pacific Blue (Serotec, Raleigh, NC), CD26-Alexa647 (Serotec), and CD335-PE (Serotec).

In a 96 -well round-bottomed plate (Nunc), $50 \mu \mathrm{L}$ of the cell suspension was added to wells containing $50 \mu \mathrm{L}$ of primary antibody cocktail. Cells then were incubated for $15 \mathrm{~min}$ at $25^{\circ} \mathrm{C}$. Following incubation, plates were centrifuged at $400 \times g$ for $2 \mathrm{~min}$, and the supernatant was decanted. A secondary antibody cocktail $(50 \mu \mathrm{L}$

Table 1. Primary and secondary antibodies used in the study

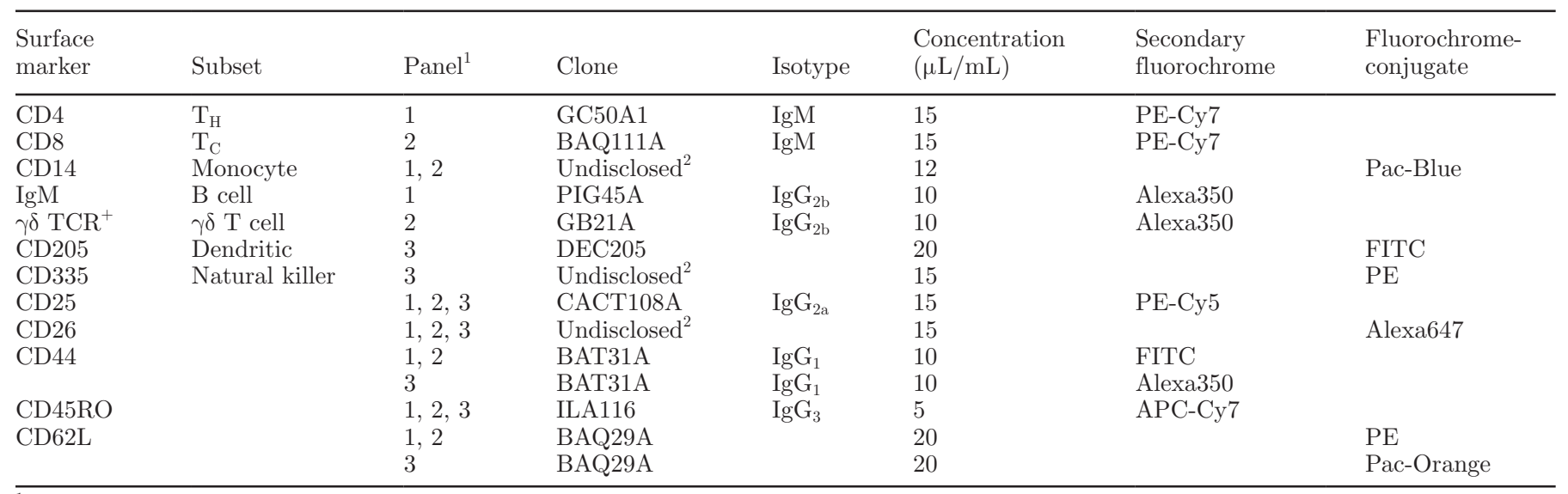

${ }^{1}$ Panel refers to the cocktail of antibodies that were in one well of the plate for staining.

${ }^{2}$ Purchased as direct conjugate; undisclosed clone. 
per well) containing isotype-specific fluorochromes was added to appropriate wells, and then incubation, centrifugation, and aspiration procedures were repeated. The plate was washed with PBS, centrifuged, aspirated twice, and then antibody-fluorochrome conjugates were added to appropriate wells, incubated, centrifuged, and decanted as described. Cells were resuspended in 200 $\mu \mathrm{L}$ of StableFix buffer (Becton Dickinson). Duplicate wells were combined and then analyzed (10,000 events within the mononuclear cell gate) by a FACScan flow cytometer (model LSRII, Becton Dickinson) for forward scatter intensity, side scatter intensity, and fluorescent intensity of each conjugated fluorochrome.

Raw data were plotted in FCS Express 3 (De Novo Software, Glendale, CA). For each leukocyte sample, side scatter intensity was plotted against forward scatter intensity to select for mononuclear cells. Within the mononuclear cell subset, side scatter intensity was plotted against the fluorescent intensity of each antibodyconjugated fluorochrome. Mononuclear cells positively expressing a given fluorochrome were determined to belong to the respective subset (Figure 1); CD205 (dendritic cells), CD335 (natural killer cells), CD26, CD44, and CD62L were less distinguishable by fluorochrome expression and are not reported. For each mononuclear cell subset, the mean fluorescent intensity and percentage of mononuclear cells were determined. Data are also presented as cellular events (mean number of cell subpopulation within 10,000 events) in Supplemental Figures S1 to S6 (http://dx.doi.org/10.3168/jds.201611144).

\section{Cytokine Analyses}

Quantification of secreted cytokines, IL-1 $\alpha$, IL-6, IFN- $\gamma$, and tumor necrosis factor- $\alpha$ in cell culture supernatants was performed using the Ciraplex multiplex assay for bovines (Cirascan; Aushon Biosystems, Billerica, MA). Bovine IL-2 was measured in cell culture supernatants using the Bovine IL-2 DuoSet ELISA kit (R\&D Systems, Minneapolis, MN).

\section{Statistical Analysis}

Data were analyzed using mixed procedures in SAS (version 9.3; SAS Institute Inc., Cary, NC). Fresh PBMC, fresh MNL, 3-d PBMC, 3-d MNL, 6-d PBMC, and 6-d MNL were all analyzed separately. Flow cytometry data for molecular expression were log-transformed to meet assumptions of normality, and then the percentage of cells belonging to each subset was analyzed as a function of vitamin treatment and in vitro treatment, which were fixed effects in the model. Calf was included in the model as a random effect and served as the experimental unit. Data met the assumption of independence; both the site of origin and calf birth weight were tested as covariates and were not significant. An $F<0.1$ for either fixed effect in the ANOVA warranted further use of contrast statements to compare respective nutritional or in vitro treatments against the appropriate control. Data are reported as mean \pm SEM; differences between least squares means were significant when $P<0.05$.

\section{RESULTS}

Mononuclear cells in peripheral blood and the mesenteric lymph node were analyzed by flow cytometry to determine the distribution of lymphocyte subsets. We first sought to state the mean percentages of mononuclear cell subsets in peripheral blood and MNL, because no previous report of mononuclear cells in the mesenteric lymph node of the calf exists, to our knowledge. Conversely, PBMC subsets are well studied in the calf. Results for freshly isolated $\mathrm{CD} 4^{+}, \mathrm{CD} 8^{+}, \gamma \delta$ $\mathrm{TCR}^{+} \mathrm{T}$-cell subsets, $\mathrm{IgM}^{+} \mathrm{B}$ cells, and CD14 ${ }^{+}$cells as percentages of PBMC and MNL across all calf treatment groups are presented in Table 2. Among total PBMC, CD $14^{+}$cells, as well as $\mathrm{CD}^{+}$and $\gamma \delta \mathrm{TCR}^{+}$ $\mathrm{T}$ cells were most abundant, averaging $25.4 \pm 1.7$, $17.0 \pm 1.2$, and $16.6 \pm 3.0 \%$, respectively. In contrast, $\mathrm{CD}^{+} \mathrm{T}$ cells and $\mathrm{IgM}^{+} \mathrm{B}$ cells were the predominant subsets observed in MNL, averaging $32.2 \pm 1.5$ and $24.9 \pm 2.1 \%$, respectively. Interestingly, $\gamma \delta \mathrm{T}$ cells were the least abundant population among the MNL cells, averaging only $6.4 \pm 0.9 \%$.

We then assessed the effects of nutritional treatments on lymphocyte distribution in fresh PBMC and MNL (Table 3). Vitamin treatments did not significantly affect peripheral or mesenteric mononuclear cell populations, but feeding colostrum replacer did significantly affect percentages of $\gamma \delta \mathrm{T}$ cell, $\mathrm{CD} 4^{+}$, and $\mathrm{CD} 8^{+}$subsets. We pooled the corresponding data from all CR-fed calves and compared them with those of CD calves, and we found that $\gamma \delta \mathrm{T}$ cells made up a lower percentage of PBMC $(P<0.01)$ in CD calves than in CR calves with or without supplemental vitamins (Figure 2). We also found that $\mathrm{CD}$ calves exhibited increased percentages of $\mathrm{CD}^{+}(P<0.05)$ and $\mathrm{CD}^{+}(P<0.005) \mathrm{T}$ cells among PBMC compared with $\mathrm{CR}$ calves, averaging $25.3 \pm 3.8$ and $15.9 \pm 2.0 \%$, respectively, for CD calves and $15.3 \pm 1.7$ and $8.6 \pm 0.9 \%$, respectively, for all CR calves. Subpopulations in fresh MNL were not affected by nutritional treatment. In fresh PBMC, colostrum did not affect CD25 expression on cell subpopulations (data not shown). However, $\gamma \delta \mathrm{T}$ cells expressed the greatest abundance of CD25, with this subset expressing CD25 at 4.6 times the intensity $(P<0.001)$ of 
other mononuclear cells that were negative for the $\gamma \delta$ T-cell receptor (Figure 3a). Lymphoid $\gamma \delta \mathrm{T}$ cells also expressed CD25 more abundantly $(P<0.001)$ than $\gamma \delta$-negative MNL, but at only 1.4 times the intensity (Figure 3b).
We measured the expression of CD45RO in lymphocyte subsets to estimate antigen-specific memory responses. Among PBMC, CD45RO was positively expressed on $39.2 \pm 4.3,28.1 \pm 1.8$, and $21.8 \pm 6.8 \%$ of $\mathrm{CD}^{+}, \mathrm{CD}^{+}$, and $\mathrm{B}$ cells, respectively, but expres-
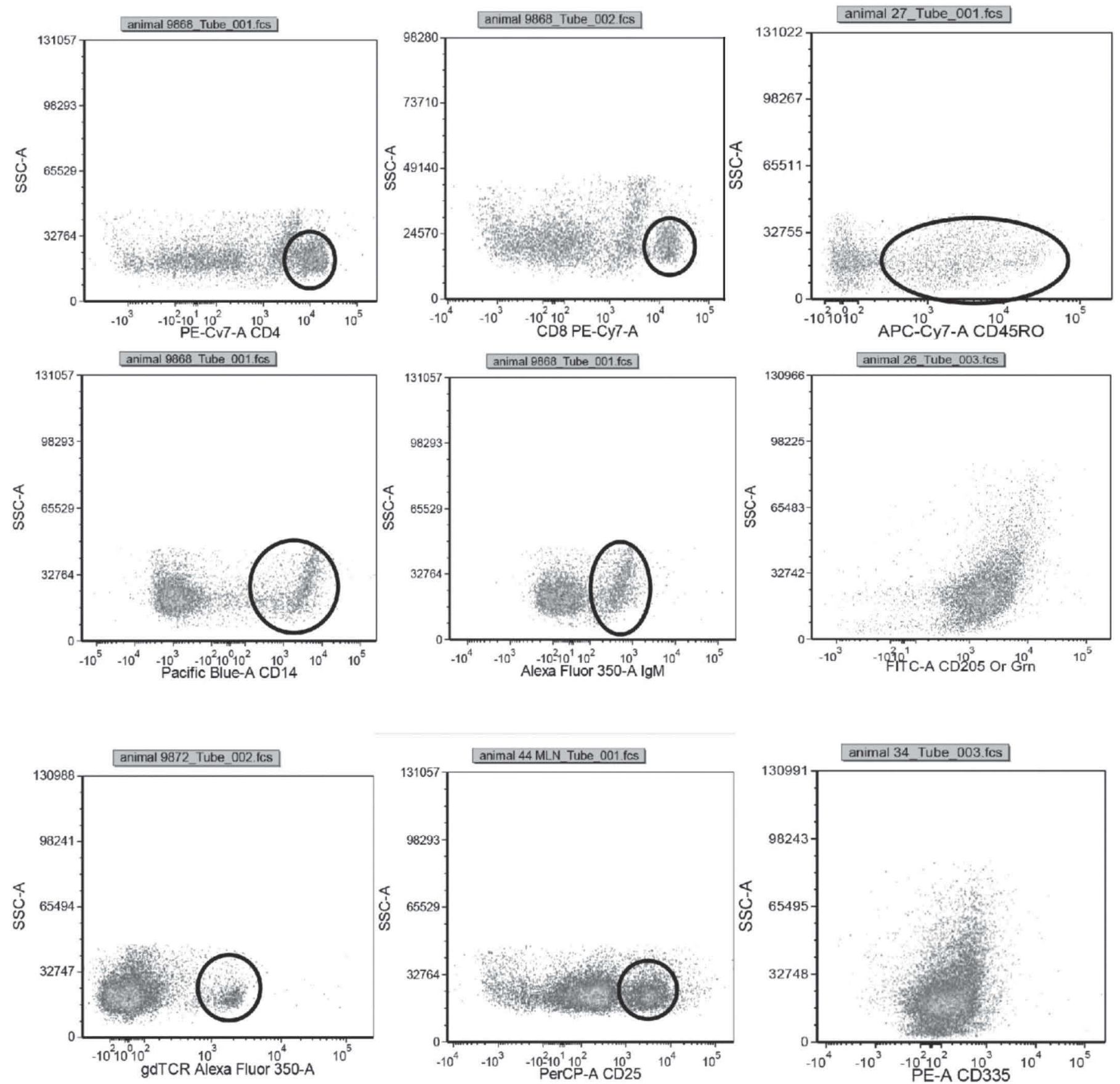

Figure 1. Example of flow cytometric panel for a calf in the study demonstrating staining of major subpopulations of cells $(\mathrm{CD} 4, \mathrm{CD} 8, \gamma \delta \mathrm{T}$ cells, B cells, monocytes, dendritic cells, natural killer cells) within peripheral blood mononuclear cells and mesenteric node lymphocyte populations, as well as 2 activation markers, CD25 and CD45RO. Ovals represent the distinct stained population of cells. SSC-A = side scatter area. 
Table 2. Distribution of cell subsets as a percentage of peripheral blood mononuclear cells (PBMC) and mesenteric node lymphocytes (MNL) across calves in all treatment groups ${ }^{1}$

\begin{tabular}{lrrrrr}
\hline & \multicolumn{5}{c}{ Cell subset } \\
\cline { 2 - 6 } Item & \multicolumn{1}{c}{$\mathrm{CD}^{+}$} & \multicolumn{1}{c}{$\mathrm{CD}^{+}$} & \multicolumn{1}{c}{$\gamma \delta \mathrm{TCR}^{+}$} & \multicolumn{1}{c}{$\mathrm{B}$ cells } & \multicolumn{1}{c}{$\mathrm{CD}^{+} 4^{+}$} \\
\hline PBMC (\%) & $17.0 \pm 1.2$ & $9.8 \pm 0.9$ & $16.6 \pm 3.0$ & $8.2 \pm 0.9$ & $25.4 \pm 1.7$ \\
MNL (\%) & $32.2 \pm 1.5$ & $14.9 \pm 0.8$ & $6.4 \pm 0.9$ & $24.9 \pm 2.1$ & $27.3 \pm 1.5$ \\
\hline
\end{tabular}

${ }^{1}$ Values are presented as means \pm SEM; $\mathrm{n}=30$.

sion was not affected by nutritional treatment (data not shown). A similar pattern emerged for expression of $\mathrm{CD} 45 \mathrm{RO}$ on $\mathrm{CD} 4^{+}$and $\mathrm{CD} 8^{+} \mathrm{T}$-cell subpopulations in MNL, but expression of CD45RO increased to $56.3 \pm$ $6.3 \%$ for B cells. Interestingly, CD45RO expression was present in extremely high $(P<0.001)$ percentages of $\gamma \delta \mathrm{TCR}^{+}$in PBMC and MNL compared with other cell subpopulations, averaging $98.6 \pm 0.3$ and $91.6 \pm 1.2$ of $\gamma \delta \mathrm{TCR}^{+}$, respectively. These data further suggest that $\gamma \delta \mathrm{T}$ cells are key responders to early infection and inflammation in both peripheral blood and lymphoid tissue.

Upon culture of PBMC and MNL with the PHA mitogen, we determined the percentage and activation of each lymphocyte subset. Differences in proliferation of cell subpopulations after culture with PHA were not apparent $(P>0.05)$ due to nutritional treatment, but PHA did result in the expansion of cell populations compared with NS cultures. An example of this is shown for $\mathrm{CD}^{+} \mathrm{T}$ cells in Figure 4. The $\mathrm{CD} 4^{+} \mathrm{T}$ cells of all CR treatment groups responded to PHA stimulation regardless of vitamin supplementation, but cells from CD calves responded less robustly to PHA than cells from CR calves. Because all treatment groups demonstrated the same trend, data were collapsed (Figure 5), with resultant increases of $\mathrm{CD}^{+}, \mathrm{CD}^{+}$, and $\mathrm{IgM}^{+}$ B lymphocyte subsets after culture with PHA for $3 \mathrm{~d}$, increasing from $13.2 \pm 1.7$ to $24.1 \pm 2.7 \%(P<0.001)$, from $10.8 \pm 0.8$ to $16.5 \pm 2.0 \%(P<0.001)$, and from $25.1 \pm 2.2$ to $35.2 \pm 2.5 \%(P<0.001)$, respectively, compared with NS cultures (medium only). In contrast, the $\gamma \delta \mathrm{TCR}^{+}$subset decreased from $23.3 \pm 2.0$ to 9.5 $\pm 1.4 \%(P<0.001)$ of total PBMC. Relative abundances of fresh PBMC in CD calves mirrored relative abundances of PHA-stimulated PBMC. We found that MNL were less affected by culture with PHA: only B cells were increased significantly $(P<0.001)$ from 30.0 \pm 2.2 to $38.4 \pm 2.3 \%$ (data not shown).

Cells were cultured separately with MPS for $6 \mathrm{~d}$ to evaluate antigen-recall responses. We detected no differences among nutritional treatments, despite the effect of colostrum on mononuclear cell subset percent-

Table 3. Distribution of cell subsets as a percentage of fresh peripheral blood mononuclear cells (PBMC) and fresh mesenteric node lymphocytes (MNL) in calves supplemented with colostrum and vitamins A, D, and $\mathrm{E}^{1,2}$

\begin{tabular}{|c|c|c|c|c|c|}
\hline \multirow[b]{2}{*}{ Item } & \multicolumn{5}{|c|}{ Cell subset } \\
\hline & $\mathrm{CD} 4^{+}$ & $\mathrm{CD}^{+}$ & $\gamma \delta \mathrm{TCR}^{+}$ & $\mathrm{B}$ cells & $\mathrm{CD} 14^{+}$ \\
\hline \multicolumn{6}{|l|}{$\overline{\mathrm{PBMC}(\%)}$} \\
\hline $\mathrm{CD}$ & $25.3 \pm 3.8^{*}$ & $15.9 \pm 2.0^{*}$ & $11.8 \pm 2.9^{*}$ & $10.4 \pm 4.0$ & $21.3 \pm 3.4$ \\
\hline $\mathrm{CR}$ & $15.4 \pm 3.2$ & $8.3 \pm 2.0$ & $22.8 \pm 3.7$ & $7.6 \pm 1.3$ & $28.3 \pm 4.9$ \\
\hline CR-A & $20.6 \pm 3.9$ & $11.4 \pm 2.4$ & $23.8 \pm 3.7$ & $11.0 \pm 2.4$ & $19.6 \pm 3.8$ \\
\hline CR-D & $11.3 \pm 4.7$ & $5.2 \pm 1.3$ & $30.6 \pm 4.8$ & $5.3 \pm 1.0$ & $27.8 \pm 4.7$ \\
\hline CR-E & $11.6 \pm 3.4$ & $7.9 \pm 1.9$ & $26.0 \pm 4.1$ & $8.7 \pm 1.4$ & $24.8 \pm 3.2$ \\
\hline CR-ADE & $17.5 \pm 3.0$ & $10.2 \pm 1.8$ & $18.7 \pm 1.7$ & $6.2 \pm 1.6$ & $30.5 \pm 5.2$ \\
\hline \multicolumn{6}{|l|}{ MNL $(\%)$} \\
\hline CD & $25.7 \pm 3.7$ & $14.3 \pm 2.6$ & $5.2 \pm 0.6$ & $19.1 \pm 3.9$ & $30.0 \pm 3.1$ \\
\hline $\mathrm{CR}$ & $31.5 \pm 1.2$ & $16.6 \pm 1.9$ & $6.7 \pm 1.4$ & $22.5 \pm 3.3$ & $26.2 \pm 1.6$ \\
\hline CR-A & $28.5 \pm 4.2$ & $14.6 \pm 1.1$ & $4.3 \pm 1.4$ & $28.7 \pm 2.2$ & $27.9 \pm 2.7$ \\
\hline CR-D & $37.9 \pm 5.3$ & $13.1 \pm 1.3$ & $5.9 \pm 1.1$ & $25.1 \pm 5.5$ & $30.4 \pm 8.5$ \\
\hline CR-E & $34.3 \pm 1.3$ & $13.8 \pm 2.0$ & $6.1 \pm 1.3$ & $35.6 \pm 8.9$ & $24.5 \pm 3.1$ \\
\hline CR-ADE & $35.5 \pm 2.3$ & $17.3 \pm 2.0$ & $10.3 \pm 5.0$ & $18.3 \pm 3.8$ & $24.8 \pm 2.5$ \\
\hline
\end{tabular}

${ }^{1}$ Values are presented as means \pm SEM; $\mathrm{n}=5$.

${ }^{2} \mathrm{CD}=$ colostrum-deprived calves; $\mathrm{CR}=$ colostrum-replete calves administered no additional vitamins; CR-A colostrum-replete calves administered retinyl palmitate; CR-D = colostrum-replete calves administered cholecalciferol; CR-E = colostrum-replete calves administered D- $\alpha$-tocopherol; CR-ADE $=$ colostrum-replete calves administered all 3 vitamins (CR-ADE).

*Significant difference $(P<0.05)$ between $\mathrm{CD}(\mathrm{n}=5)$ and combined CR-fed calves $(\mathrm{n}=25)$. 


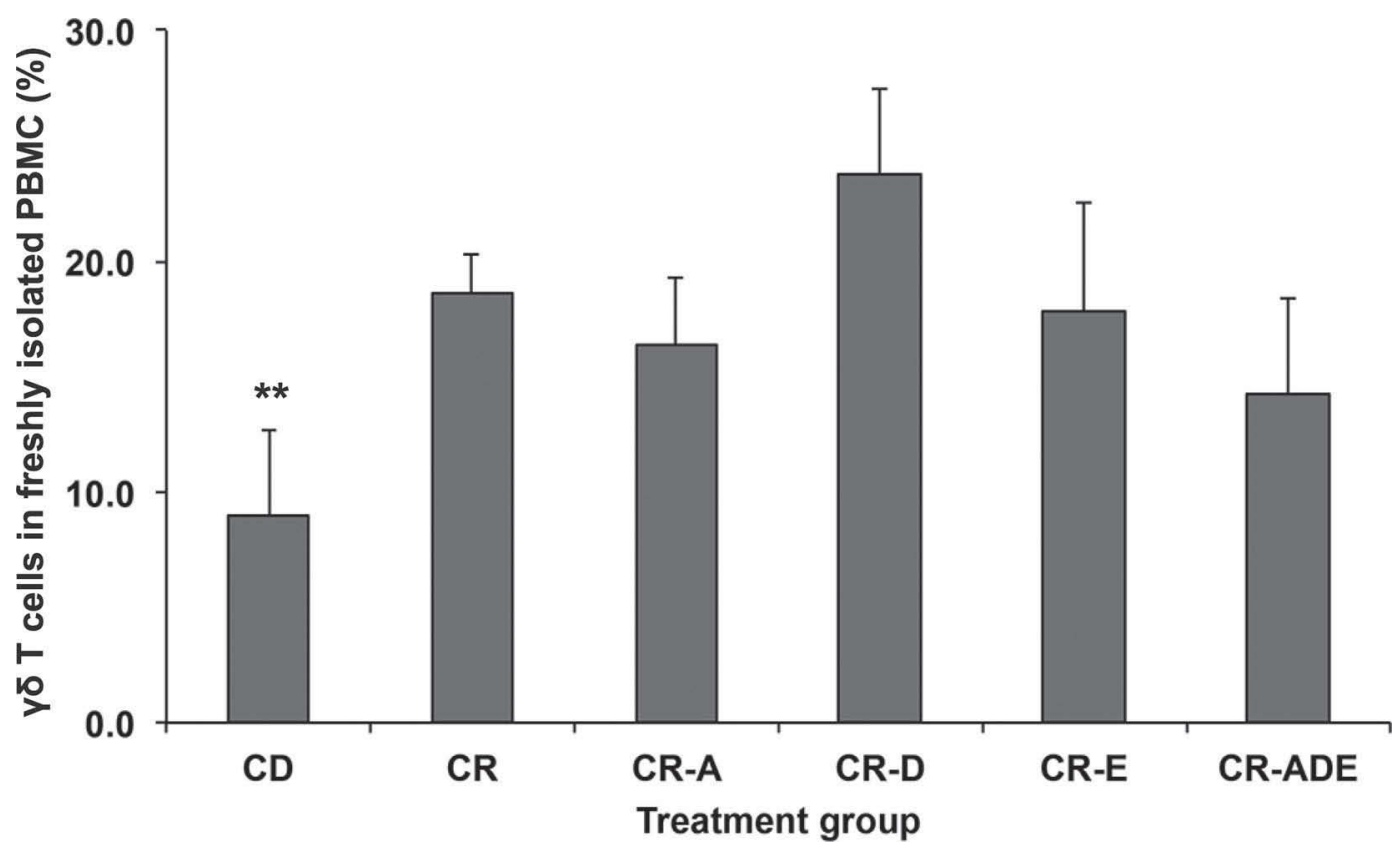

Figure 2. Percentage of $\gamma \delta$ T cells in freshly isolated peripheral blood mononuclear cells (PBMC) from colostrum-deprived calves (CD), or colostrum-replete calves administered no additional vitamins (CR), retinyl palmitate (CR-A), cholecalciferol (CR-D), D- $\alpha$-tocopherol (CR-E), or all 3 vitamins (CR-ADE) and challenged with live Mycobacterium avium ssp. paratuberculosis for 14 d. Data are expressed as means \pm SEM; ${ }^{* *} P<0.01$ for CD compared with CR, CR-A, CR-D, CR-E, and CR-ADE treatment groups; $\mathrm{n}=5$ per treatment.

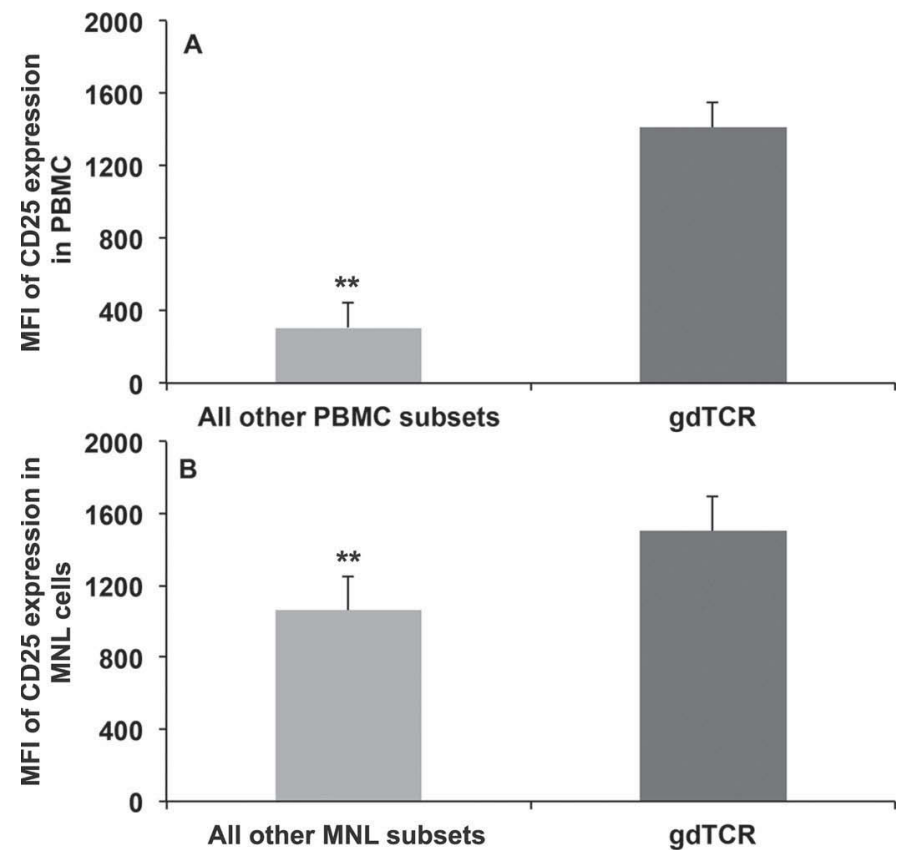

Figure 3. Mean fluorescent intensity (MFI) of CD25 expression on freshly isolated $\gamma \delta \mathrm{T}$ cells (gdTCR) compared with all other peripheral blood mononuclear cell (PBMC) subsets (A) and all other mesenteric node lymphocyte (MNL) subsets (B) obtained on d 14 of the study. Results are summarized across calves in all treatment groups. Data are expressed as means \pm SEM; ${ }^{* *} P<0.01 ; \mathrm{n}=30$.

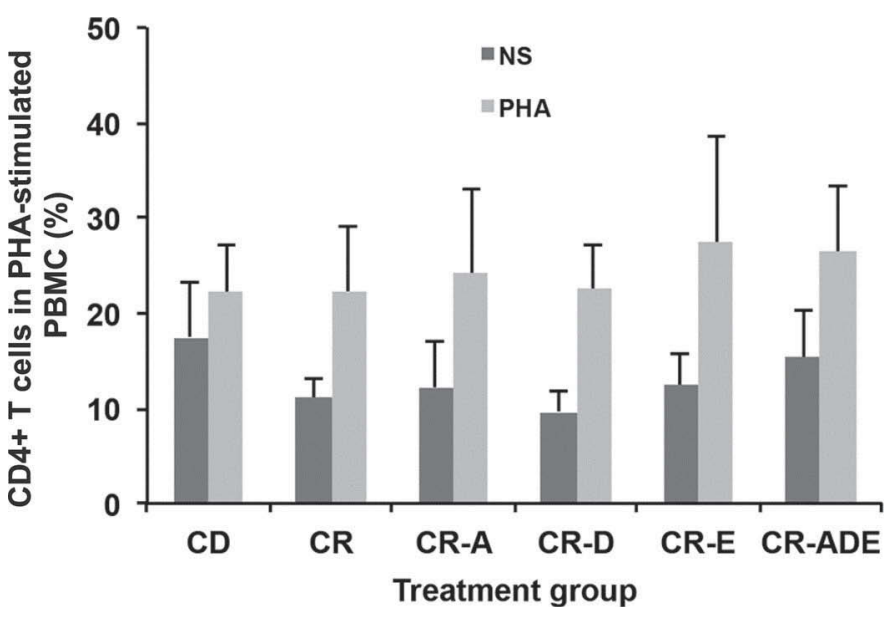

Figure 4. Percentage of $\mathrm{CD}^{+} \mathrm{T}$ cells in total peripheral blood mononuclear cells (PBMC) isolated on d 14 of the study from colostrum-deprived calves (CD) or colostrum-replete calves administered no additional vitamins $(\mathrm{CR})$, retinyl palmitate (CR-A), cholecalciferol (CR-D), D- $\alpha$-tocopherol (CR-E), or all 3 vitamins (CR-ADE) and challenged with live Mycobacterium avium ssp. paratuberculosis for $14 \mathrm{~d}$. Peripheral blood mononuclear cells were cultured for $3 \mathrm{~d}$ with medium alone (nonstimulated, NS) and phytohemagglutinin (PHA). Results are summarized across calves in all treatment groups. Data are expressed as means $\pm \mathrm{SEM} ; \mathrm{n}=5$ per treatment. 


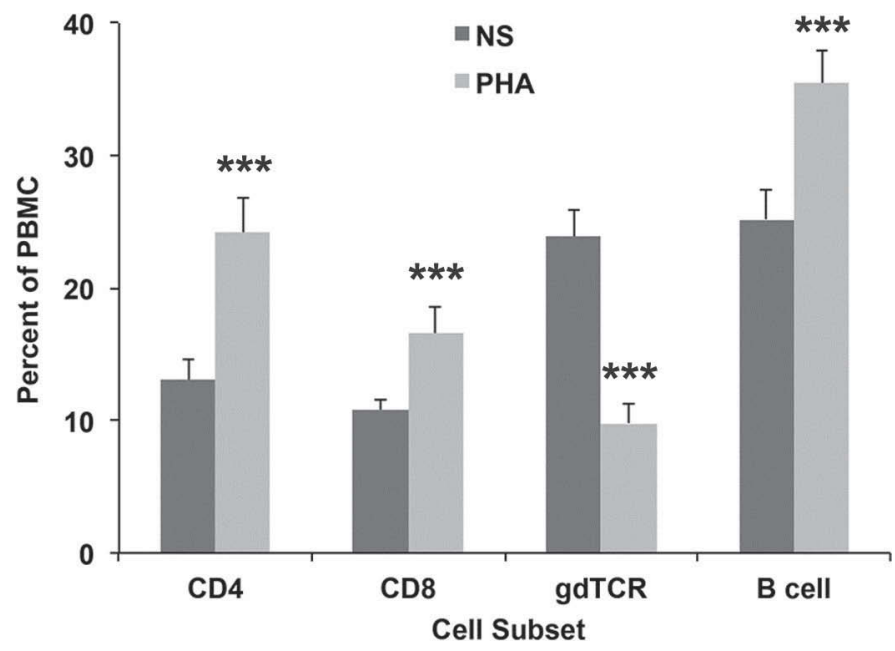

Figure 5. Percentages of $\mathrm{CD} 4^{+}, \mathrm{CD} 8^{+}, \gamma \delta \mathrm{T}$ cells (gdTCR), and B cells in total peripheral blood mononuclear cells (PBMC) isolated on d 14 of the study and cultured for 3 d with medium alone (nonstimulated, NS) and phytohemagglutinin (PHA). Results are summarized across calves in all treatment groups. Data are expressed as means \pm SEM; $* * * P<0.001 ; \mathrm{n}=30$

ages in fresh samples. We found that PBMC generally exhibited a response characterized by increased B lymphocyte and decreased $\mathrm{T}$ lymphocyte percentages (Figure 6). Compared with NS cultures, T-cell subpopulations of $\mathrm{CD}^{+}, \mathrm{CD}^{+}$, and $\gamma \delta \mathrm{TCR}^{+}$all decreased as a percentage of PBMC by $24.2(P<0.01), 33.6(P<$ $0.001)$, and $18.8 \%(P<0.001)$, respectively, upon exposure to MAP antigen. In contrast, incubation of PBMC for $6 \mathrm{~d}$ in the presence of antigen resulted in a $28.4 \%$ increase $(P<0.001)$ in $\mathrm{B}$ cells. Although stimulation of MNL with MAP antigen resulted in similar changes to $\mathrm{CD} 4+, \mathrm{CD} 8+$, and B lymphocyte subsets, $\gamma \delta \mathrm{TCR}^{+}$ $\mathrm{T}$ cells increased $(P<0.001)$ from $7.4 \pm 0.7$ to $13.4 \pm$ $1.4 \%$ of MNL (Figure 7 ).

Secretion of proinflammatory cytokines IL-1 $\beta$ and IL- 6 by cultured PBMCs was not affected by vitamin supplementation (data not shown), but we observed a significant $(P<0.05)$ increase in IFN- $\gamma$ secretion for CR-D calves compared with other calves $(118 \pm 54$ vs. $23 \pm 6 \mathrm{pg} / \mathrm{mL}$ ) after culture of PBMCs with medium alone. In addition, we noted trends for increased secretion of IL-6 (821 \pm 211 vs. $405 \pm 95 \mathrm{pg} / \mathrm{mL})$ and IFN- $\gamma(881 \pm 244$ vs. $394 \pm 112 \mathrm{pg} / \mathrm{mL})$ for CD calves compared with $\mathrm{CR}$ calves $(P<0.09)$ after mitogen stimulation of cells. Only negligible amounts of IL-2 were measurable in cell culture supernatants, regardless of stimulant or treatment group (data not shown).

\section{DISCUSSION}

Results of this study demonstrate that $\gamma \delta \mathrm{TCR}^{+} \mathrm{T}$ lymphocytes are key participants in neonatal immunity. A primary observation is that $\mathrm{CD}$ calves exhibited decreased percentages of $\gamma \delta \mathrm{TCR}^{+} \mathrm{T}$ cells among PBMCs within the first 2 weeks of life compared with $\mathrm{CR}$ calves. Lymphocytes are present in mammary gland secretions before parturition and through the end of lactation (Park et al., 1992). However, the pasteurization, fractionation, and spray-drying procedures involved in manufacturing the colostrum replacer used in

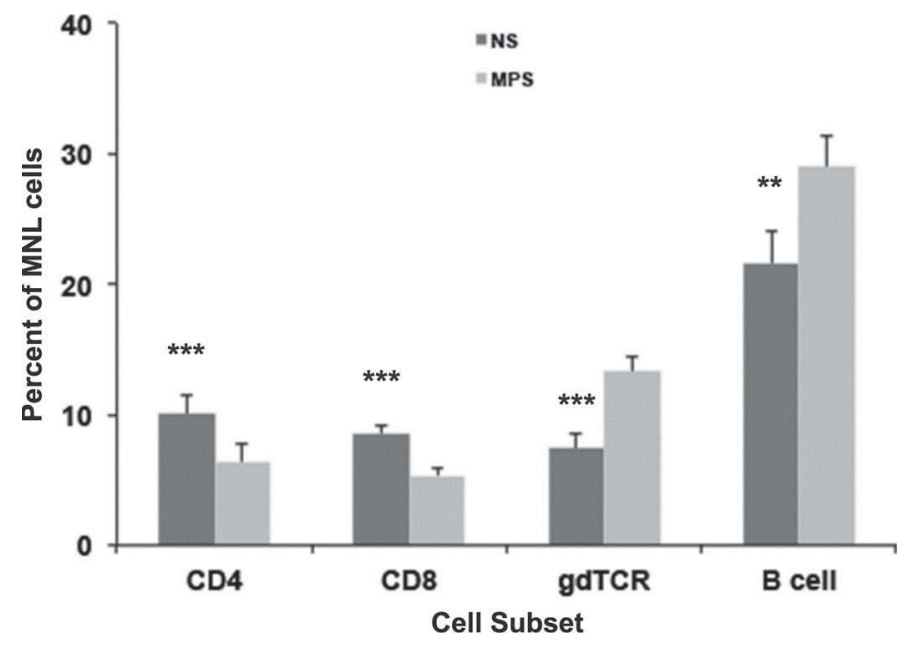

Figure 7. Percentages of $\mathrm{CD} 4^{+}, \mathrm{CD} 8^{+}, \gamma \delta \mathrm{T}$ cells (gdTCR), and $\mathrm{B}$ cells in total mesenteric node lymphocytes (MNL) isolated on d 14 of the study and cultured for $6 \mathrm{~d}$ with medium alone (nonstimulated, NS) and a whole cell sonicate of Mycobacterium avium ssp. paratuberculosis (MPS). Results are summarized across calves in all treatment groups. Data are expressed as means $\pm \mathrm{SEM}$; ${ }^{* *} P<0.01$, ${ }^{* * *} P<$ $0.001 ; \mathrm{n}=30$. 
this study exclude the possibility that the calf passively acquired viable maternal leukocytes. Thus, one or more compounds in colostral whey may have affected the proportion of $\gamma \delta \mathrm{T}$ cells in peripheral blood in calves, likely through an indirect mechanism involving activation of an immune response. In contrast, we observed no effect of vitamin supplementation on lymphocyte distribution, proliferative ability, or antigen-recall responses to MAP. We had previously demonstrated that serum levels of vitamins $\mathrm{A}, \mathrm{D}$, and $\mathrm{E}$ in neonatal calves were increased by injectable/oral supplementation in the respective treatment groups (CR-A, CR-D, CR-E, CR-ADE) (Krueger et al., 2016). Feeding pasteurized whole milk from d 1 to 14 of the study resulted in adequate levels of dietary vitamin $\mathrm{A}$ for all calves regardless of supplementation, although supplemented calves (CR-A and CR-ADE) had higher levels of serum retinol than nonsupplemented calves. In contrast, CD or CR calves that did not receive supplemental vitamin $\mathrm{D}$ or $\mathrm{E}$ had negligible serum levels of these vitamins by d 14, and fell into the range of deficiency for both of these vitamins. With such obvious differences in calves' nutritional status due to vitamin supplementation, it was interesting that this finding did not manifest as observed differences in immune response in the present study. Vitamins $\mathrm{A}, \mathrm{D}_{3}$, and $\mathrm{E}$ have been implicated in various roles pertaining to Th1 signaling and T-cell receptor sensitivity (Nonnecke et al., 2010; Sacco et al., 2012). The Th2-like B-cell response to MPS noted in the present study suggests that these roles may be less involved in the recognition of and responses to the MAP pathogen.

Lymphocyte populations in neonatal calves have been studied extensively. As reviewed by Chase et al. (2008), $\mathrm{IgM}^{+} \mathrm{B}$ cells may comprise less than $5 \%$ of circulating lymphocytes, but early antigen encounters stimulate clonal expansion of this subset within weeks. Young calves that were experimentally infected intratonsillarly with MAP from 2 to 5 wk of age exhibited humoral reactivity to a $\sim 50-\mathrm{kDa}$ antigen of MAP (Waters et al., 2003), and calves exhibited B-cell responses to the pathogen by 3 mo of age (Stabel et al., 2011), demonstrating capabilities for early response. It is known that $\mathrm{CD}^{+}$and $\mathrm{CD} 8^{+} \mathrm{T}$ cells comprise about 20 and $10 \%$ of peripheral neonatal lymphocytes, respectively, and maintain a 2:1 ratio of relative abundance through adulthood (Chase et al., 2008). The findings of the present study agree with these previous reports. In further agreement with the present findings, $\gamma \delta \mathrm{T}$ cells are known to make up about $25 \%$ of circulating neonatal lymphocytes and to decrease in relative abundance during the first $5 \mathrm{mo}$ of age (Chase et al., 2008). In fact, $\gamma \delta$ $\mathrm{T}$ lymphocytes were among the first cells recruited to subcutaneous sites of experimental MAP infection in 5- to 6-wk-old calves (Plattner et al., 2013). Identification of this T-cell subset as a key responder during early MAP infection is thus not unprecedented.

The identification of increased CD25 expression among peripheral $\gamma \delta \mathrm{T}$ cells indicates that the abundance of this activated lymphocyte subset in neonates might be linked to IL-2 signaling. Indeed, when PBMC were cultured with PHA for $3 \mathrm{~d}$, we observed proliferative responses of $\mathrm{CD} 4^{+}, \mathrm{CD} 8^{+}$, and $\mathrm{B}$ lymphocytes, but $\gamma \delta \mathrm{T}$ cells declined as a percentage of PBMC. We did not attempt to isolate any of the lymphocyte subsets to quantify proliferating cell nuclear antigen or caspases that would further identify the percentage changes as proliferative or apoptotic in nature, nor did we measure cell subset-specific cytokines. The percentage changes of $\mathrm{CD} 4^{+}$and $\mathrm{CD} 8^{+} \mathrm{T}$ cells we observed in $3 \mathrm{~d}$ culture, however, agreed with previous observations that PHA is a lymphocyte mitogen that induces Th1 cytokine signaling (Epstein et al., 1971; Lis and Sharon, 1977). Interleukin-2 is the principal cytokine responsible for T-cell proliferation and is the first to be secreted upon T-cell activation (Abbas et al., 2012). Furthermore, $\gamma \delta$ $\mathrm{T}$ cells have been shown to proliferate in an IL-2-mediated autocrine fashion in response to Mycobacterium tuberculosis antigen (Janis et al., 1989). The greater relative intensity with which fresh $\gamma \delta \mathrm{T}$ cells expressed CD25 compared with other PBMC indicates that these cells were likely activated before PHA stimulation, whereas other $\mathrm{T}$ and $\mathrm{B}$ lymphocytes were activated only upon mitogen treatment. Thus, the apparent paucity of peripheral $\gamma \delta \mathrm{T}$ cells among fresh PBMC in CD calves and among $\mathrm{PBMC}$ of all calves after mitogen treatment should not be interpreted as $\gamma \delta$ T-cell inadequacy, but rather as an indication that other lymphocyte subsets were activated for proliferation.

Two mechanisms potentially explain the lower percentage of $\gamma \delta \mathrm{T}$ cells in CD calves. The whey fraction of colostrum in the colostrum replacer used in this study contained biologically active, non-nutritive compounds, including $\operatorname{IgG}_{1}$ antibodies, complement, and cytokines (Stelwagen et al., 2009). Collectively, these compounds promote Th2-biased immunity in the neonate to accommodate microbial exposure at birth (Chase et al., 2008). In the absence of colostrum, neonatal calves lack the adaptive, neutralizing defenses of passively acquired immunity and are at increased risk for pathogen stimulation of proinflammatory Th1 responses, as was noted to a certain extent in the present study by increased proinflammatory cytokine secretion. This first mechanism, however, cannot completely account for the apparent Th1 activation observed; acute-phase proteins indicative of endogenous inflammation were not different at d 7 or d 14 of age in CD or CR calves in this study (Krueger et al., 2016). Only at d 1 of age 
were acute-phase proteins different, because CD calves failed to acquire haptoglobin in the first $24 \mathrm{~h}$ of life. Haptoglobin has been shown to participate in antigen presentation and the generation of antibody-mediated recall responses (Huntoon et al., 2008). Thus, the evidence supports a secondary mechanism by which haptoglobin and other non-nutritive colostral compounds divert neonatal immune signaling to a Th2 bias, under which $\gamma \delta \mathrm{T}$ cells remain a predominant cell type.

Stimulation of PBMC for 6 d with MPS did not result in shifts in $\mathrm{T}$ lymphocyte percentages similar to stimulation by PHA. Instead, $\mathrm{CD} 4^{+}, \mathrm{CD}^{+}$, and $\gamma \delta \mathrm{T}$ cells all decreased as a percentage of PBMC, whereas $\mathrm{B}$ cells increased. The proliferation of $\mathrm{B}$ cells without concurrent expansion of T-cell subsets suggests a Th2biased response to MPS. Interestingly, the percentage of MNL $\gamma \delta \mathrm{T}$ cells was expanded in response to MPS, but percentage changes of other lymphocyte subsets were similar to those of PBMC. The contradictory responses of peripheral and lymphoid $\gamma \delta \mathrm{T}$ cells may be explained by the lower relative expression of CD25 by fresh MNL $\gamma \delta \mathrm{T}$ cells compared with those in PBMC. Whereas fresh peripheral $\gamma \delta \mathrm{T}$ cells were hyperexpressive for CD25, indicating an antigen-activated state, lymphoid $\gamma \delta \mathrm{T}$ cells were less activated before antigen stimulation. Culture with MPS induced expansion of the lymphoid $\gamma \delta$ T-cell subset, which is indicative of IL-2 autocrine signaling amid a Th2 response. This dynamic result further implies that neonatal lymphoid $\gamma \delta \mathrm{T}$ cells are primed for broader participation in Th2biased responses during immune development.

Results of this study agree with previously reported data characterizing $\gamma \delta \mathrm{T}$ cells in the bovine neonate. The $\gamma \delta$ T cells can become primed by pathogen-associated molecular patterns for increased responsiveness to IL-2 without becoming fully activated (Jutila et al., 2008). Furthermore, $\gamma \delta \mathrm{T}$ cells are a predominant lymphocyte subset in bovine neonates and can participate in early proinflammatory responses by secreting IFN- $\gamma$ (Ramsburg et al., 2003; Taschuk and Griebel, 2012). Responses of this specialized $\mathrm{T}$ lymphocyte subset to intracellular infection, especially by Mycobacterium species, have been extensively studied. For example, $\gamma \delta$ $\mathrm{T}$ cells proliferate in response to $M$. tuberculosis antigens through an IL-2-mediated mechanism (Janis et al., 1989; Constant et al., 1994). Subsequent activation by non-peptide mycobacterial antigens induces IFN- $\gamma$ and is enhanced by IL-12 (García et al., 1997). Interestingly, IL-12 secretion is suppressed in the neonatal calf by endogenous and maternal glucocorticoids (Visser et al., 1998; Chase et al., 2008). Conclusions from these studies ultimately support a role for $\gamma \delta \mathrm{T}$ cells in defense against intracellular pathogens that is indepen- dent of inflammation, highlighting the importance of the subset in Th1-suppressed neonatal calves.

\section{CONCLUSIONS}

Colostrum-deprived calves had decreased $\gamma \delta$ T-cell percentages in PBMC, indicating increased Th1 immune signaling during early life. The $\gamma \delta \mathrm{T}$ cells of young calves expressed IL-2 receptor and CD45RO more intensely than other lymphocyte subsets, but did not further proliferate in response to PHA; thus, $\gamma \delta \mathrm{T}$ cells may be activated independently of inflammation and are likely a key effector subset during Th2-biased neonatal immune development. Neonatal lymphoid $\gamma \delta$ $\mathrm{T}$ cells retained capacity for antigen-provoked proliferation and responded to MAP antigen in vitro amid a broader Th2-like response.

\section{ACKNOWLEDGMENTS}

The authors thank Margaret Walker (National Animal Disease Center, Ames, IA) for her help with laboratory assays, and Brian Conrad (National Animal Disease Center, Ames, IA), Ben Samek (Iowa State University, Ames, IA), and Hannah Schroeder (NADC, Ames, IA) for their excellent work with the neonatal calves.

\section{REFERENCES}

Abbas, A. K., A. H. Lichtman, and S. Pillai. 2012. Basic Immunology: Functions and Disorders of the Immune System. 2nd ed. Elsevier Health Sciences, Philadelphia, PA.

Chase, C. C., D. J. Hurley, and A. J. Reber. 2008. Neonatal immune development in the calf and its impact on vaccine response. Vet. Clin. North Am. Food Anim. Pract. 24:87-104.

Constant, P., F. Davodeau, M. A. Peyrat, Y. Poquet, G. Puzo, M. Bonneville, and J. J. Fournie. 1994. Stimulation of human gamma delta $\mathrm{T}$ cells by nonpeptidic mycobacterial ligands. Science 264:267-270.

Epstein, L. B., M. J. Cline, and T. C. Merigan. 1971. The interaction of human macrophages and lymphocytes in the phytohemagglutininstimulated production of interferon. J. Clin. Invest. 50:744-753.

García, V. E., P. A. Sieling, J. Gong, P. F. Barnes, K. Uyemura, Y. Tanaka, and R. L. Modlin. 1997. Single-cell cytokine analysis of gamma delta $\mathrm{T}$ cell responses to nonpeptide mycobacterial antigens. J. Immunol. 159:1328-1335.

Harris, N. B., and R. G. Barletta. 2001. Mycobacterium avium ssp. paratuberculosis in veterinary medicine. Clin. Microbiol. Rev. 14:489-512.

Huntoon, K. M., Y. Wang, C. A. Eppolito, K. W. Barbour, F. G. Berger, P. A. Shrikant, and H. Baumann. 2008. The acute phase protein haptoglobin regulates host immunity. J. Leukoc. Biol. 84:170-181.

Janis, E. M., S. H. Kaufmann, R. H. Schwartz, and D. M. Pardoll. 1989. Activation of gamma delta $\mathrm{T}$ cells in the primary immune response to Mycobacterium tuberculosis. Science 244:713-716.

Jutila, M. A., J. Holderness, J. C. Graff, and J. F. Hedges. 2008. Antigen-independent priming: A transitional response of bovine $\gamma \delta$ T-cells to infection. Anim. Health Res. Rev. 9:47-57. 
Krueger, L. A., D. C. Beitz, K. Onda, M. Osman, M. R. O'Neil, S. Lei, F. H. Wattoo, R. L. Stuart, H. D. Tyler, and B. Nonnecke. 2014. Effects of D- $\alpha$-tocopherol and dietary energy on growth and health of preruminant dairy calves. J. Dairy Sci. 97:3715-3727.

Krueger, L. A., T. A. Reinhardt, D. C. Beitz, R. L. Stuart, and J. R. Stabel. 2016. Effects of colostrum and vitamins A, D, and E on haptoglobin and clinical health in neonatal Holstein calves challenged with Mycobacterium avium ssp. paratuberculosis. J. Dairy Sci. 99:2884-2895.

Lis, H., and N. Sharon. 1977. Lectins: Their chemistry and application to immunology. The Antigens. Vol 4. M. Sela, ed. Academic Press, London, UK.

Nonnecke, B. J., M. R. Foote, B. L. Miller, D. C. Beitz, and R. L. Horst. 2010. Short communication: Fat-soluble vitamin and mineral status of milk replacer-fed dairy calves: Effect of growth rate during the preruminant period. J. Dairy Sci. 93:2684-2690.

Park, Y. H., L. K. Fox, M. J. Hamilton, and W. C. Davis. 1992. Bovine mononuclear leukocyte subpopulations in peripheral blood and mammary gland secretions during lactation. J. Dairy Sci. 75:998-1006.

Plattner, B. L., E. L. Huffman, and J. M. Hostetter. 2013. Gammadelta T-cell responses during subcutaneous Mycobacterium avium subspecies paratuberculosis challenge in sensitized or naive calves using matrix biopolymers. Vet. Pathol. 50:630-637.

Ramsburg, E., R. Tigelaar, J. Craft, and A. Hayday. 2003. Age dependent requirement for gamma delta $\mathrm{T}$ cells in the primary but not secondary protective immune response against an intestinal parasite. J. Exp. Med. 198:1403-1414.

Robison, J. D., G. H. Stott, and S. K. DeNise. 1988. Effects of passive immunity on growth and survival in the dairy heifer. J. Dairy Sci. 71:1283-1287.

Sacco, R. E., B. J. Nonnecke, M. V. Palmer, W. R. Waters, J. D. Lippolis, and T. A. Reinhardt. 2012. Differential expression of cyto- kines in response to respiratory syncytial virus infection of calves with high or low circulating 25-hydroxyvitamin D3. PLoS ONE 7:e33074.

Stabel, J. R., J. P. Bannantine, S. Eda, and S. Robbe-Austerman. 2011. Induction of B cell responses upon experimental infection of neonatal calves with Mycobacterium avium ssp. paratuberculosis. Clin. Vaccine Immunol. 18:1139-1149.

Stabel, J. R., L. Bradner, S. Robbe-Austerman, and D. C. Beitz. 2014. Clinical disease and stage of lactation influence shedding of $\mathrm{Myco}$ bacterium avium subspecies paratuberculosis into milk and colostrum of naturally infected dairy cows. J. Dairy Sci. 97:6296-6304.

Stelwagen, K., E. Carpenter, B. Haigh, A. Hodgkinson, and T. T. Wheeler. 2009. Immune components of bovine colostrum and milk. J. Anim. Sci. 87:3-9.

Streeter, R. N., G. F. Hoffsis, S. Bech-Nielsen, W. P. Shulaw, and D. M. Rings. 1995. Isolation of Mycobacterium paratuberculosis from colostrum and milk of subclinically infected cows. Am. J. Vet. Res. 56:1322-1324.

Taschuk, R., and P. J. Griebel. 2012. Commensal microbiome effects on mucosal immune system development in the ruminant gastrointestinal tract. Anim. Health Res. Rev. 13:129-141.

Visser, J., A. van Boxel-Dezaire, D. Methorst, T. Brunt, E. R. De Kloet, and L. Nagelkerken. 1998. Differential regulation of interleukin-10 (IL-10) and IL-12 by glucocorticoids in vitro. Blood 91:4255-4264.

Waters, W. R., J. M. Miller, M. V. Palmer, J. R. Stabel, D. E. Jones, K. A. Koistinen, E. M. Steadham, M. J. Hamilton, W. C. Davis, and J. P. Bannantine. 2003. Early induction of humoral and cellular immune responses during experimental Mycobacterium avium ssp. paratuberculosis infection of calves. Infect. Immun. 71:5130 5138 . 